\title{
Educational Communication in Virtual Worlds and Videoconference
}

\author{
http://dx.doi.org/10.3991/ijet.v9i9.4190 \\ N. Tapsis and K. Tsolakidis \\ University of the Aegean, Rhodes, Greece
}

\begin{abstract}
During the last few years an increase of the offered distance learning programs is observed, resulting in a need for corresponding tools. Within this context, the present study examines comparatively Virtual Worlds and Videoconferencing, as supporting tools for the educational communication and dialogue in distance learning. Analysing media theories, in order to compare the two media, we observe that the virtual space itself, and its relationship with the user, could affect the educational communication and the educational activities from distance.
\end{abstract}

Index Terms-distance learning, media theories, videoconference, virtual world.

\section{INTRODUCTION}

Dialogue in education is part of every educational process. Specifically, in Moore's Transactional Distance Theory, dialogue is considered an important dimension of any distance learning program. In recent years there is a strong concern about the potential of media to serve the communication needs of an educational program. Within this framework, a variety of theories determining the used media and the communication's characteristics in a distance learning scheme, are defined. In this work the specific ways, in which two methods: videoconferencing and virtual world together with their corresponding technologies, can support educational dialogue in distance education, are examined.

\section{MEDIA THEORIES}

Each media theory sets a media evaluation criterion and classifies the media according to this criterion. Media Richness Theory (MRT) sets as criterion the richness of the medium, Media Synchronicity Theory (MST) the synchronicity of the medium and Media Naturalness Theory (MNT) the naturalness of the medium. In order to evaluate the communication performance, MRT focuses on the communication task, while MST on the communication process and MNT on the communication preferences of the communicants.

\section{A. Media Richness Theory}

According to MRT, a rich medium for a communication task is one that provides best the set of capabilities needed for the specific circumstances of a distance learning project. These are: the task to be achieved, the involved individuals and the social context within which they interact [12]. Daft \& Lengel, developers of the theory, define information richness as the: "ability of information to change understanding within a time interval" [10]. So, rich communication is associated with quick understanding; the faster the understanding of a message, the richer the communication channel.

Depending on their technical characteristics, media can establish communication in a different time; so they differ in the degree of understanding that can be achieved at a particular time. The faster you reach understanding, the richer is the medium for this type of task. Dennis \& Valacich state that no medium can be characterized as rich in all situations [12].

\section{B. Media Synchronicity Theory}

Synchronicity is a state of the communicants, while media synchronicity is a medium's property. Synchronicity is defined as: "the degree to which individuals work together in the same activity, with the same information and at the same time, with a common focus" [12], while media synchronicity is defined as "the ability of a medium to create the sense that all participants are concurrently engaged in the communication event" [7].

MST argues that the communication performance depends on the capability of the medium to support the communication process during a task function [12], and there is no perfect tool for any situation. The efficiency of a communication performance depends on the degree of matching the synchronicity of a medium with the needs of the communication task. The ideal choice may not be a single medium, but a method which combines several media, taking into account the positive and negative characteristics of each selected medium (see Table 1).

TABLE I.

Relative Trait SALIENCE of SElEcted Media

\begin{tabular}{|l|c|c|c|c|c|}
\hline & $\begin{array}{c}\text { Immediacy } \\
\text { of feed- } \\
\text { back }\end{array}$ & $\begin{array}{c}\text { Symbol } \\
\text { variety }\end{array}$ & $\begin{array}{c}\text { Paral- } \\
\text { lelism }\end{array}$ & $\begin{array}{c}\text { Rehears- } \\
\text { ability }\end{array}$ & $\begin{array}{l}\text { Repro- } \\
\text { cessabil- } \\
\text { ity }\end{array}$ \\
\hline Face to face & high & $\begin{array}{c}\text { low- } \\
\text { high }\end{array}$ & low & low & low \\
\hline $\begin{array}{l}\text { Video } \\
\text { conference }\end{array}$ & $\begin{array}{c}\text { medium- } \\
\text { high }\end{array}$ & $\begin{array}{c}\text { low- } \\
\text { high }\end{array}$ & low & low & low \\
\hline $\begin{array}{l}\text { Synchro- } \\
\text { nous } \\
\text { groupware }\end{array}$ & $\begin{array}{l}\text { low- } \\
\text { medium }\end{array}$ & $\begin{array}{c}\text { low- } \\
\text { high }\end{array}$ & high & $\begin{array}{c}\text { medi- } \\
\text { um- } \\
\text { high }\end{array}$ & high \\
\hline
\end{tabular}

Source: Ref.[12]

For the VWs, immediacy of feedback, symbol variety, parallelism and rehearsability can be considered mediumhigh, while reprocessability low. 


\section{Media Naturalness Theory}

Key-concept for the MNT is the communication overload. The term communication overload over the years has been referred to as cognitive overload [23] or information overload [13]. Cho, Ramgolam, Schaefer and Sandlin [8] studying the way in which synchronicity affects communication overload, found that the communicants felt heavier load with low synchronicity media, than with high synchronicity media. For this reason, Kock [15] argues that due to the long experience of people with face to face communication, they are more likely to choose to communicate through a high synchronicity medium, since it gives a closer to face to face experience.

The negative effects of the non-naturalness of a medium can be balanced by what is referred to as "schema alignment" and "cognitive adaptation". The schema alignment construction refers to the similarity between the mental schemas of an individual and those of other participants, in the communication task. The cognitive adaptation construct refers to an individual's level of schema development associated with the use of a particular medium. Acceptance is maximized when the conferencing system provides a realistic virtual presence between users [9].

Conclusively, in order to test the effectiveness of communication, it is necessary to examine: (i) the medium's technical affordances in transferring information (richness of the medium), (ii) the capability for synchronization of communicating parties offered by the medium, (synchronicity of the medium) and (iii) participant's familiarity with the use of the medium (naturalness of medium, or adoption among prospective users).

\section{VIDEOCONFERENCE AND VIRTUAL WORLD}

\section{A. Videoconference}

$\mathrm{VC}$ is a system that supports transferring of information in the form of text, audio and video, from one user to other users on different locations. These applications mainly support data transferring rather than storing data within a shared online space. For that reason they can be used only in a synchronous setting. Zhang and Tang [26] note that the main properties of VC are: high interactivity and relatively small scale. Scale is the maximum number of connected users/locations that can participate in an audio or video conference depending on the technical capabilities of the medium. Lately, VC can be used for groups of up to 25 users/locations, while a VW, for example Second Life, can support up to about 40-70 users/locations.

\section{B. Virtual World}

Virtual Worlds are Multi Users Virtual Environments (MUVE) capable of synchronous communication and are considered social networking applications. Another special feature they have is the simulated three-dimensional environment they create.

Among various definitions for VW, others focus on the user and others in the technical environment.

According Bell a VW is: "a continuous network of people represented as avatars and facilitated by networked computers" [27], while the Horizon Report defines as: "a custom setting that is reflecting the real world" [28] and Dickey as "a networked desktop virtual reality in which users move and interact in simulated three-dimensional spaces" [29].

Following Burton's classification [30], a VW can be characterized as a $3 \mathrm{D}$ virtual environment because of : (i) the vector geometry used, (ii) the ability of the user to change the visual angle to the environment, (iii) the capability of interaction of the user with elements of the virtual environment and (iv) in three-dimensional sound.

\section{VIRTUAL ENVIRONMENT}

Three-dimensional virtual learning environments are applications of constructivist learning theories [31], which offer more possibilities for action for the participants, supporting "learning by doing" contrary to "learning by reading".

There are several definitions about virtual environments (VE). Calleja provides a definition which fits mostly with the 3D environments, as "... computer generated domains which create a perception of space and permit modification through the exertion of agency" [6]. This definition separates the 2D virtual environments, like chat rooms and web pages, from 3D virtual environments, like VWs.

The users of an environment are represented within the environment by a virtual agent, "avatar", which is not just a neutral object, but a virtual one with behavior, motion in space and having a semantic meaning. Finally, the avatar is the personal virtual object of the user. User behavior can be influenced by its indirect interaction with other online users, ie interaction through avatars. Moreover McCreery, Krach, Schrader and Boone [19] in their research found that people's personality and the personality of their avatar, influences behaviors in virtual environments.

The main characteristics of a VE are the 3D-like virtual space, the real-time graphics and the fact that it can be viewed interactively with other users, although each user may have a different point of view. The last characteristic brings the VE more close to the real physical experience comparing with the experience from the environment of a VC. So the most characteristic difference between VW and $\mathrm{VC}$ is on the interface which they offer to user. The interface of $\mathrm{VW}$ is a shared environment generated on a server by its users, while the interface of a VC is generated on the user's computer.

\section{A. Presence in a virtual environment}

The process of learning in face to face situations is implemented in different physical locations depending on the type of learning interaction sought in every case. For example, the interaction of the teacher with his students is taking place mainly in classroom, teacher-student interaction can take place in the office of the teacher, student's interaction with learning material can take place in a private place, in the library, etc. So usually the kind of a physical environment is related to the activity which has to be performed.

Hence, users relate the environment they find themselves in, with the activity that takes place in it. Therefore the capability of changing the virtual environment according to the needs of the learning activity facilitates user's adaptation.

The adoption of an educational environment depends on its characteristics and the requirements of the expected interaction according to the adopted learning model. 
When the student "finds himself" within an environment, he develops a sense of presence, a user's experience. However, the concept of presence was analyzed only after the emergence of virtual environments.

Some researchers approach the concept of "presence" as a property of the communication medium [20], while others as a property of the user of the communication medium [4]. According to Lee, the presence stands for: "a psychological state in which the virtuality of experience is unnoticed" [17]. In general, researchers agree that the construct of presence relates to a sense of being there or being connected.

There are many kinds of presence that have been suggested. Bulu in his research [5] found that some specific kinds of presence are related with satisfaction and immersive tendencies of students. For example the virtual place itself and the co-presence can affect student's satisfaction and immersive tendencies in the VW and not the social presence in general. According to Wheeler [25], social presence is essential in any pedagogical situation and mostly in online programs. Kawachi supports that the dimensions of social presence are [14]:

1. Time: duration of engagement, integrating rhythm, synchronization performance and making moments signify.

2. Place: It has to do with body sense, the emotional space, the material impact and the situated agency.

3. Action: It is connected with tuning, reciprocity, negotiation and quality of deeds.

4. Relation: It relates with communion, engagement, reputation and use.

Each kind of presence has a different role in each stage of the educational process. Social presence is important in the early stages of the learning process carrying the student from being an outsider to becoming an insider in the online community. Social presence integrates the outsider into the target community, and there serves to reduce anxiety [14]. For the next stages of the educational process the cognitive presence is essential, helping student to reach collaborative learning.

\section{B. Interaction, collaboration and learning in virtual environment}

As discussed earlier, theories that define and characterize media are focusing on different aspects of them. MRT is focusing on the volume of information that can be transferred from the medium, considering that the richest medium can carry more information. MST is interested in the flow of information that reaches the user, with respect to synchronization between transmitter and receiver (transmission speed of information to user). MNT is concerned about the quality of information that can reach the users, based on their personal needs and preferences. MNT focuses on what the user receives, considering "natural" the medium that is closer to his habits.

The need for interaction is determined by:

1. Content to be taught (required media richness MRT),

2. Learning scenario applied (required media synchronicity - MST) and

3. Individual user (necessary user's background MNT).
According Ward \& Sonneborn [24], the key technical features of VWs which affect collaboration and learning are:

1. possibility to modify one's avatar,

2. possibility to import, modify and interact with 3D objects,

3. physical cues and

4. possibility for individuals to personalize their group work experience.

Research shows that the actions of individuals within a virtual environment are connected to the degree that the users feel connected to the above environment [1]. So, one's feelings about the environment may affect one's interaction within this environment. Van der Straaten [22] considers that interaction depends on the capabilities of the medium. If the medium transfers small amount of information to and from the user, it can reduce the opportunities for interaction and perception. Some theoreticians suggest that online communication cannot transfer as much information as the face to face communication. For example Bulu considers that the on-line interaction loses in non-verbal aspects (eg emotionality), although it wins in time flexibility, space flexibility and content continuity [5].

Biocca [3] considers that the nature of the interface affects the adaptability of the human mind and body and finally the way one interacts with other people or objects through Computer Mediated Communication (CMC), since according to O'Brien there is a close association of perception and action.

The role of interaction for online communication can be better understood through three dimensions in interactivity recommended by Liu: active control, two-way communication, and synchronicity [18]. Through these dimensions the user attempts to gain control over communication. This objective may result in a greater social presence, which in turn can lead to greater satisfaction from the educational process.

Another issue concerning communication is security and trust among interacting students. Often it is considered that in online communication the necessary transparency required to cultivate trust is missing. Nonetheless Bente, Ruggenberg, Kramer and Eschenburg argue that VWs enhance trust and this is a VW's specific benefit for distributed collaboration and learning [2].

So it seems that some researchers' skepticism towards distance education is rooted in the following beliefs:

1. Mediated communication, as compared to face to face communication, hinders the transmission of emotional messages,

2. Mediated communication hinders the development of trust.

The learning model in 3D VLEs developed by Dalgarno and Lee [11] considers that the learner interaction in 3D VLE is achieved through embodied actions, embodied verbal \& non-verbal communication, control of environment attributes and behavior and building/scripting of objects and behaviors.

Their model argues that "learner interaction" and "representational fidelity of the virtual environment" can affect: (i) the construction of identity of the user, (ii) the sense of presence and (iii) the co-presence that influences the afforded learning tasks, and in turn it affects the effi- 
ciency of the learning model applied, resulting better learning benefits.

It seems that working students prefer online interactivity in order to balance work and lifestyle needs with their education. They appeared less concerned about learning benefits [16]. Therefore, online learning appears to be successful, not only on physical distance, but also on the issue of limited free time for studies, due to the modern lifestyle obligations.

\section{DISCUSSION}

To compare the performance of $\mathrm{VW}$ versus $\mathrm{VC}$, over a communication task, one has to examine the degree that their corresponding characteristics affect communication.

\section{A. Virtual environment}

VC does not create a shared virtual space, but it provides a personal interface in which every user can manage the information that is received from other users. On the other hand, VW creates a permanent virtual space which can be visited by anyone independently from other users. So it is more akin to a web page, through which users can communicate in a synchronous or asynchronous way. VW creates an artificial environment through virtual reality, where the users communicate in a natural way through audioconference. The environment of a VW is designed according a predefined communication scenario, something impossible for the environment of $\mathrm{VC}$ and this makes "schema alignment" and "cognitive adaptation" more possible.

\section{B. Communication}

As for the way VW and VC handle the elements of a message (spoken code, written code, nonverbal communication), the two media transfer the oral and written speech in the same way, although VW additionally supports 3D audio conference, giving an immersive sense to users. Nevertheless there is a huge difference in the possibilities for nonverbal communication that the two environments offer (communication among users through avatars and communication between user and content).

\section{Semiotics and metaphors}

Each environment provides its users with tools for expression and communication. As tools of expression, VWs provide symbol sets, such as for the appearance and motion of the avatar, gestures, or other predefined behaviors of the avatar. The effectiveness of use of these elements depends on the degree of familiarity of the user with this specific communication code. As very often the users are not aware of this communication code, VW has very high learning curve, compared to other media that do not use such communication codes. In the last few years some VC systems (as Google plus) offer some additional accessories, as image or audio morphing, emoticons, etc.

\section{Scale of the medium}

The two media differ in the size of communication group they can support efficiently. VC is used more often for personal communication or for communication in small groups. Unlike that, VW is a medium for social networking, offering tools for mass communication and cooperation. For this reason it has several organizing levels of the user's contacts: (i) personal contacts (friends), (ii) group participation (groups) and (iii) nearby residents. It is worth noticing that the space is used as one of the criteria for grouping online users. Through this common space, users are grouped around the specific content of the environment. There is also a scale difference which is connected with the ergonomy of the two interfaces. In the interface of VC the picture from the "other user" is static in one place, but in the interface of VW the "other user" can be moved closer or away as in a physical environment. Due to the difference in medium scale, VWs can support collaboration of bigger groups than VC.

\section{E. Content's saving}

Transfer and storage of content are important when group communication process is a conveyance procedure. A MUVE, depending on its nature, can save some kind of content that is necessary for the activities of its users. VWs are not intended to create standard content files (like doc, pdf, etc type) and therefore they don't have the appropriate tools to create and edit them. Instead they have tools to create and edit simple text, three-dimensional objects and programming scripts. All other types of content can only be projected into the environment. Videoconferencing is not developed to create and store content, but only delivery and viewing. Due to the possibility of viewing content, VW user can only study the content when he is online, a fact that enhances synchronicity. However, as this content is displayed as part of the overall environment, (eg. web pages projected onto the surfaces of the objects), reading is not as easy as when a user looks at a web page.

\section{F. Communication's procedures}

It should be noted that often the opportunity for local saving of files, gives a greater sense of security to the user, since one can study their content offline, more autonomously. As the content lies constantly into VW, the user can come back again to study individually the information. Therefore, VW can support conveyance procedures, provided the users are online. Some other environments offer better support to the conveyance procedures than VWs, as they offer options of printing. A VW includes two important sup-applications: building and scripting. These applications give educator the opportunity to apply a lot of complicated learning scenarios.

Following MRT's approach, VW is considered "too much" for the transmission of simple messages, while it can be more efficient for the transmission of complex messages, ie equivocality tasks. VC is better for the transformation of raw personal information, while $\mathrm{VW}$ is better for more coded symbolic information and interaction. It has to be noted that a VC has poor possibilities for asynchronous use, while a VW has much more, as a user can interact with the in-world content.

VW has an advantage in convergence procedures, because it facilitates user interaction, visually and acoustically. Users have a strong sense of the "other's presence" into virtual space, a feature that not only facilitates communication, but also concentration of the users on it, resulting in a mutual understanding. This feature enhances synchronicity of the medium.

In previous research it was observed that students were more satisfied with the VW environment, or that they found it more pleasant comparing with a LMS [21]. This shows a positive attitude towards VW since it provides a 
game-like condition which reduces emotional stress. Based on MNT [15], VW is considered a more natural communication medium than VC.

\section{CONCLUSION}

Although both applications use synchronous communication, their main difference is on the environment/interface they create for the user. VW is an authentic virtual environment, while $\mathrm{VC}$ is not an environment at all [6]. This affects the user's sense of presence, something which may be important for some educational procedures. $\mathrm{VC}$ is an advanced videophone, while VW is a shared virtual space. It is certainly easier to use a videophone than an entire world, which requires initial development and greater adaptation to its techniques, ie a higher learning curve.

Each communication task asks for a different level of media richness, or media synchronicity. VC is advantageous for transmission of the real-physical picture from the user's private space, while VW is advantageous for the transmission of a symbolic picture constructed by the user. Human's experience from face to face communication asks for a complete environment, real or virtual, that could provide rich information in the right speed. $\mathrm{VW}$ is closer to the first, while VC to the second. VW is an adjustable environment from its designer, something that gives a lot of opportunities to educators, while $\mathrm{VC}$ is a ready-to-use environment. Moreover one has to think about the opportunities each medium gives for the communication between the user-student and the content one has to learn. So, each communication task demands a different combination of media, according to their characteristics, ie richness, synchronicity and naturalness.

It seems that the ideal choice of a medium for an educational program can only come through the deeper knowledge of: (a) characteristic properties of all available media, (b) degree of familiarity of instructors and students with each medium and (c) teaching subject.

In any case, a key question that must be answered by designers of distance education programs is "whether, and to what extent, an environment is essential in the educational process they design" For example, if an educational program aims only to delivery educational material, it would be pointless to use videoconferencing or virtual world, but if it aims only to resolve queries remotely then videoconferencing would be satisfactory. In the case that a collaborative learning is preferred, then a virtual world could be one of the potential options.

\section{REFERENCES}

[1] R. M. Banos, C. Botella, I. Rubio, S. Quero, A. Garcia-Palacios and M. Alcaniz, "Presence and emotions in virtual environments: The influence of stereoscopy," CyberPsychology \& Behavior, vol. 11.1, pp. 1-8, 2008. http://dx.doi.org/10.1089/cpb.2007.9936

[2] G. Bente, S. Ruggenberg, N. C. Kramer and F. Eschenburg, "Social presence and interpersonal trust in net-based collaboration," Human Communications Research, 34, pp.287-318, 2008. http://dx.doi.org/10.1111/j.1468-2958.2008.00322.x

[3] F. Biocca, "The Cyborg's dilemma: Embodiment in virtual environments," Journal of Computer-Mediated Communication, vol. 03.2, pp.12-26, 1997.

[4] F. Biocca and C. Harms, "Defining and measuring social presence: Contribution to the networked minds theory and measure," Proceedings of PRESENCE 2002, pp.7-36, 2002.

[5] S. T. Bulu, "Place presence, social presence, co-presence, and satisfaction in virtual worlds," Computers and Education, 58, pp.154-161， 2012. http://dx.doi.org/10.1016/j.compedu.2011. $\underline{08.024}$

[6] G. Calleja, "Virtual worlds today: gaming and online sociality," Online - Heidelberg Journal of Religions on the Internet, vol. 03.1, 2008. [http://archiv.ub.uni-heidelberg.de/volltextserver/8 288/]

[7] J. R. Carlson and J. F. George, "Media appropriateness in the conduct and discovery of deceptive communication: The relative influence of richness and synchronicity," Group Decision and Negotiation, vol. 13.2, pp.191-210, 2004. http://dx.doi.org/10.1023/ B:GRUP.0000021841.01346.35

[8] J. Cho, D. I. Ramgolam, K. M. Schaefer and A. N. Sandlin, "The Rate and Delay in Overload: An Investigation of Communication Overload and Channel Synchronicity on Identification and Job Satisfaction," Journal of Applied Communication Research, vol. 39.1, pp.38-54, 2011. http://dx.doi.org/10.1080/00909882.2010. $\underline{536847}$

[9] G. A. Coudriet and J. E. Babich, "Effective Design of Audio/Video Conference Rooms," Sound and Vibration, Acoustical Publications, Inc. vol. 46.7, 2012.

[10] R. L. Daft and R. H. Lengel, "Organizational information requirements, media richness and structural design," Management Science, vol. 32.5, pp.554-571, 1986. http://dx.doi.org/10.1287/ mnsc.32.5.554

[11] B. Dalgarno and M. J. W. Lee, "What are the learning affordances of 3-D virtual environments?" British Journal of Educational Technology, vol. 41.1, pp.10-32, 2010. http://dx.doi.org/10.1111/ j.1467-8535.2009.01038.x

[12] A. R. Dennis and J. S. Valacich, "Rethinking media richness: Towards a theory of media synchronicity," Proceedings of the 32nd Hawaii International Conference on Systems Sciences, 1, pp.1-10, 1999.

[13] M. J. Eppler and J. Mengis, "The concept of information overload: A review of literature from organization science, accounting, marketing, MIS, and related disciplines," The information society, vol. 20.5, pp.325-344, 2004. http://dx.doi.org/10.1080/0197224 0490507974

[14] P. Kawachi, "Online social presence and its correlation with learning," International Journal of Social Media and Interactive Learning Environments, vol. 1.1, pp.19-31, 2013. http://dx.doi.org/10.1504/IJSMILE.2013.051653

[15] N. Kock, "Media richness or media naturalness? The evolution of our biological communication apparatus and its influence on our behavior toward e-communication tools," IEEE Transactions on Professional Communication, vol. 48.2, pp.117-130, 2005.

[16] R. K. Ladyshewsky and R. Taplin, "Factors influencing mode of study preferences in post-graduate business students," The International Journal of Management Education, vol. 11.1, pp.34-43, 2013.

[17] K. M. Lee, "Presence, explicated," Communication Theory, vol. 14.1, pp.27-50, 2004. http://dx.doi.org/10.1111/j.14682885.2004.tb00302.x

[18] Y. Liu, "Developing a Scale to Measure the Interactivity of Websites," Journal of Advertising Research, vol. 43.2, pp.207-216, 2003.

[19] M. P. McCreery, S. K. Krach, P. G. Schrader and R. Boone, "Defining the virtual self: Personality, behavior and the psychology of embodiment," Computers in Human Behavior, vol. 28, pp.976-983, 2012. http://dx.doi.org/10.1016/j.chb.2011.12.019

[20] J. Short, E. Williams and B. Christie, The social psychology of telecommunications, London: John Wiley \& Sons, 1976.

[21] N. Tapsis, Alternative forms of education: The use of virtual worlds in e-learning, PhD Thesis, University of the Aegean, 2012.

[22] P. Van der Straaten, "Interaction Affecting the Sense of Presence in Virtual Reality,". Delft University of Technology, Faculty of Information Technology and Systems, pp.2-7, 2000.

[23] T. E. Vollmann, "Cutting the Gordian knot of misguided performance measurement,". Industrial Management \& Data Systems, vol. 24.1, pp.24-26, 1991. http://dx.doi.org/10.1108/026355791 10138126

[24] T. Ward and M. Sonneborn, "Creative expression in virtual worlds: Imitation, imagination, and individualized collaboration," 
PAPER

EDUCATIONAL COMMUNICATION IN VIRTUAL WORLDS AND VIDEOCONFERENCE

Psychology of Aesthetics, Creativity, and the Arts, vol. 3.4, pp.211-221, 2009. http://dx.doi.org/10.1037/a0016297

[25] S. Wheeler, "Creating social presence in digital learning environments: A presence of mind?" TAFE Conference, Queensland, Australia, 11 November 2005.

[26] L. Zhang and X. Tang, "Client assignment for improving interactivity in distributed interactive applications," IEEE, Proceedings of IEEE INFOCOM., 2011.

[27] M. Bell, "Toward a Definition of Virtual Worlds," Journal of Virtual Worlds Research, vol. 1.1, pp. 1-5, 2008.

[28] Horizon Report, The New Media Consortium and EDUCAUSE learning initiative, Austin, Texas, 2007. Retrieved from http://www.nmc.org/pdf/2007_Horizon_Report.pdf

[29] M. D. Dickey, "Three-dimensional virtual worlds and distance learning: two case studies of Active Worlds as a medium for distance education," British Journal of Educational Technology, vol. 36.3 , pp. 439-451, 2005. http://dx.doi.org/10.1111/j.14678535.2005.00477.x

[30] B.G. Burton, Collaboration and the use of three dimensional interface within a virtual learning environment and the impact on communication and learning: a case study. 2008. [http://mospace.umsystem.edu/xmlui/handle/10355/5600]

[31] B. Carter and A. Click, "Imagine the real in the virtual: Experience your second life," 22nd Annual Conference on Distance Teaching and Learning, Wisconsin, Madison, 2006. [http://www.uwex.edu/disted/conference/resource library/proceed ings/06_4202.pdf]

\section{AUTHORS}

N. Tapsis has a $\mathrm{PhD}$ on Alternative forms of education at the University of the Aegean, Greece. Now he is teacher of physics at secondary education in Rhodes, Greece (email: tapsis@aegean.gr).

K. Tsolakidis is Associate Professor at the University of the Aegean, Greece (e-mail: tsolak@aegean.gr).

Submitted 02 October 2014. Published as rsubmitted by the authors 30 October 2014. 